06;09

\title{
Инициирование детонации световым импульсом в тонком заряде пиротехнического состава ВC-2
}

\author{
() С.И. Герасимов ${ }^{1-4}$, М.А. Илюшин ${ }^{5}$, П.Г. Кузнецов ${ }^{2}$, С.М. Путис ${ }^{5}$, С.А. Душенок ${ }^{5}$, В.С. Роженцов ${ }^{1}$ \\ ${ }^{1}$ Российский федеральный ядерный центр - Всероссийский научно-исследовательский институт экспериментальной \\ фозики, Саров, Россия \\ ${ }^{2}$ Саровский фризико-технический институт — филиал Научно-исследовательского ядерного университета „МИФИ“, \\ Саров, Россия \\ ${ }^{3}$ Нижегородский государственный технический университет им. Р.Е. Алексеева, Нижний Новгород, Россия \\ 4 Институт проблем машиностроения РАН - филиал Института прикладной физики РАН, Нижний Новгород, Россия \\ ${ }^{5}$ СКТБ „Технолог“, Санкт-Петербург, Россия \\ E-mail: s.i.gerasimov@mail.ru
}

Поступило в Редакцию 30 июля 2020г.

В окончательной редакции 16 октября 2020 г.

Принято к публикации 16 октября 2020 г.

\begin{abstract}
Представлены результаты инициирования пленочных зарядов пиротехнического состава ВС-2 лампамивспышками. Впервые показано, что импульсное излучение ламп-вспышек вызывает в пленке состава ВC-2 детонацию, скорость которой составляет $\sim 4300 \mathrm{~m} / \mathrm{s}$, а в алюминиевой пластине-свидетеле - деформацию, глубина которой зависит от толщины пленочного заряда состава ВC-2.
\end{abstract}

Ключевые слова: состав ВС-2, лампа-вспышка, детонация.

DOI: 10.21883/PJTF.2021.03.50567.18490

Взрывы зарядов светочувствительного пиротехнического состава ВС-2, состоящего из 90\% комплексного перхлората ртути (II) [1] и 10\% ПВМТ (оптически прозрачного сополимера 2-метил-5-винилтетразола и метакриловой кислоты по ТУ 38-403-208-88), были успешно инициированы как импульсным излучением твердотельных лазеров [2], так и лучом лазерного диода [3]. Подробно свойства светочувствительного состава ВC-2 описаны в работе [4].

Лампы-вспышки являются альтернативными лазерными источниками импульсного светового излучения видимого диапазона, вызывающими взрыв зарядов состава BC-2 [5]. Лампами-вспышками в отличие, например, от лазерных диодов можно осуществить одновременное инициирование протяженных зон светочувствительных составов [6]. Целью работы является изучение возбуждения и развития взрыва при облучении пленочных зарядов состава ВC-2 импульсами некогерентного светового излучения.

На начальном этапе работы было необходимо оценить минимальную толщину пленки состава ВС-2 (кислородный баланс состава ВС-2+8.7\%), которая гарантировала бы распространение в ней детонации. Мы допустили, что толщина пленочного заряда, обеспечивающая переход его горения в детонацию при облучении лампой-вспышкой, может быть пропорциональна минимальному заряду, определенному, например, по гексогену в гильзе от капсюля-детонатора № 8 при возбуждении пленки тепловым импульсом [7]. Проведенные испытания показали, что минимальный заряд пленки состава ВС-2, вызвавший детонацию запрессованного заряда гексогена, составил $14 \pm 1 \mathrm{mg}$ (среднее по четырем экспериментам). Сле- довательно, пленка состава ВС-2 толщиной несколько десятков микрометров обеспечит протекание в ней детонации при возбуждении тепловыми источниками. Приведенные оценочные данные были использованы при изготовлении экспериментальных пленочных образцов зарядов состава ВС-2 размером $10 \times 80 \mathrm{~mm}$ с плотностью $\sim 1.2 \mathrm{~g} / \mathrm{cm}^{3}$ и толщиной $\sim 0.55 \mathrm{~mm}$ (заряды № 1 и 2) или $\sim 0.82 \mathrm{~mm}$ (заряды № 3 и 4), нанесенных на полированные алюминиевые листы (ГОСТ 1018) размером $23 \times 100 \times 0.15 \mathrm{~mm}$. Рентгеновская дефектоскопия полученных образов (заряды № 1-4) состава ВС-2 (рентгеновский аппарат РЕИС-100И, Россия) показала, что пленочные заряды состава ВC-2 нанесены на алюминиевую фольгу неравномерно (имеются трещины покрытия, пустоты, плотности пленки состава ВС-2 на отдельных участках заряда отличаются от средней величины).

На следующем этапе работы заряды № 1-4 состава ВC-2 (предварительно закрепленные на алюминиевой пластине-свидетеле) облучались лампой-вспышкой ЭВИС-3, представляющей собой две пластины из оргстекла с шириной зазора $0.1 \mathrm{~mm}$, соединенные миллиметровой стримерной дорожкой (металлизированной лавсановой пленкой) длиной $90 \mathrm{~mm}$ и толщиной $\sim 1 \mu \mathrm{m}$; время светового импульса $\sim 1.5 \mu \mathrm{s}$. Соединение и размещение оборудования в экспериментах осуществлялись в соответствии со схемой, представленной на рис. 1.

Цифровой осциллограф LeCroy WS 24Xs-A (США) регистрировал длительность вспышки ЭВИС-3 (яркостная температура $\sim 1.2 \cdot 10^{4} \mathrm{~K}$, плотность мощности облучения вблизи источника $\sim 10^{4} \mathrm{~W} / \mathrm{cm}^{2}$, энергия разрядного контура $150 \mathrm{~J}$ ), экспозицию с электронно- 


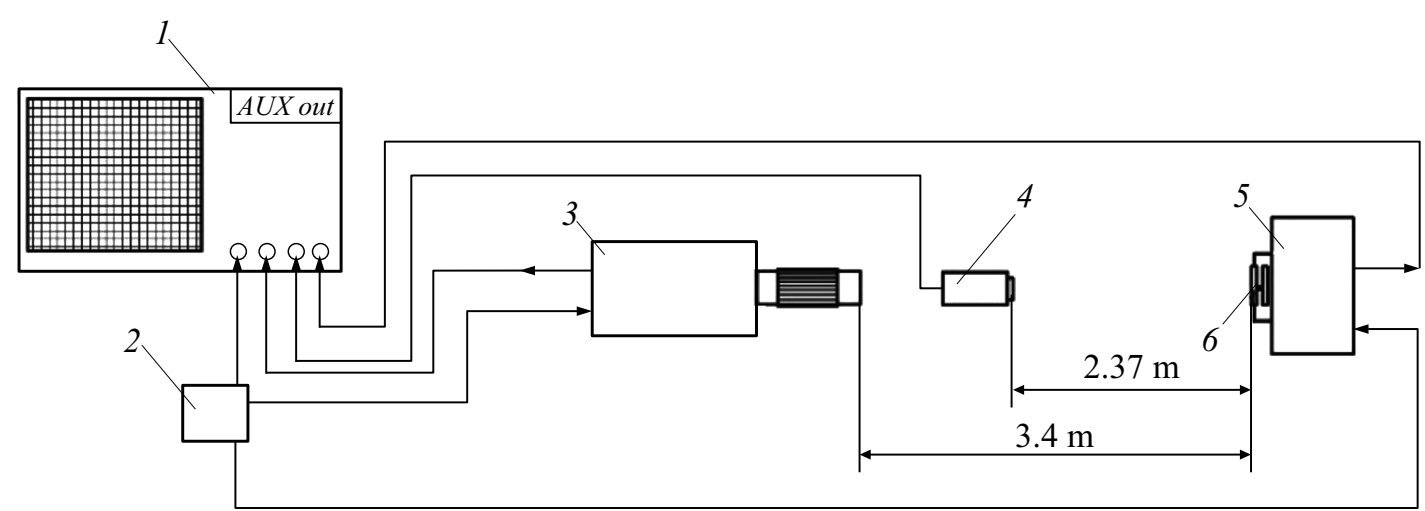

Рис. 1. Схема размещения и соединения оборудования. 1 - цифровой осциллограф, 2 - блок согласования, $3-$ электроннооптическая камера Наногейт 22/2, 4 - широкодиапазонный электронно-оптический фотометр, 5 - импульсный источник света, 6 - объект испытания.
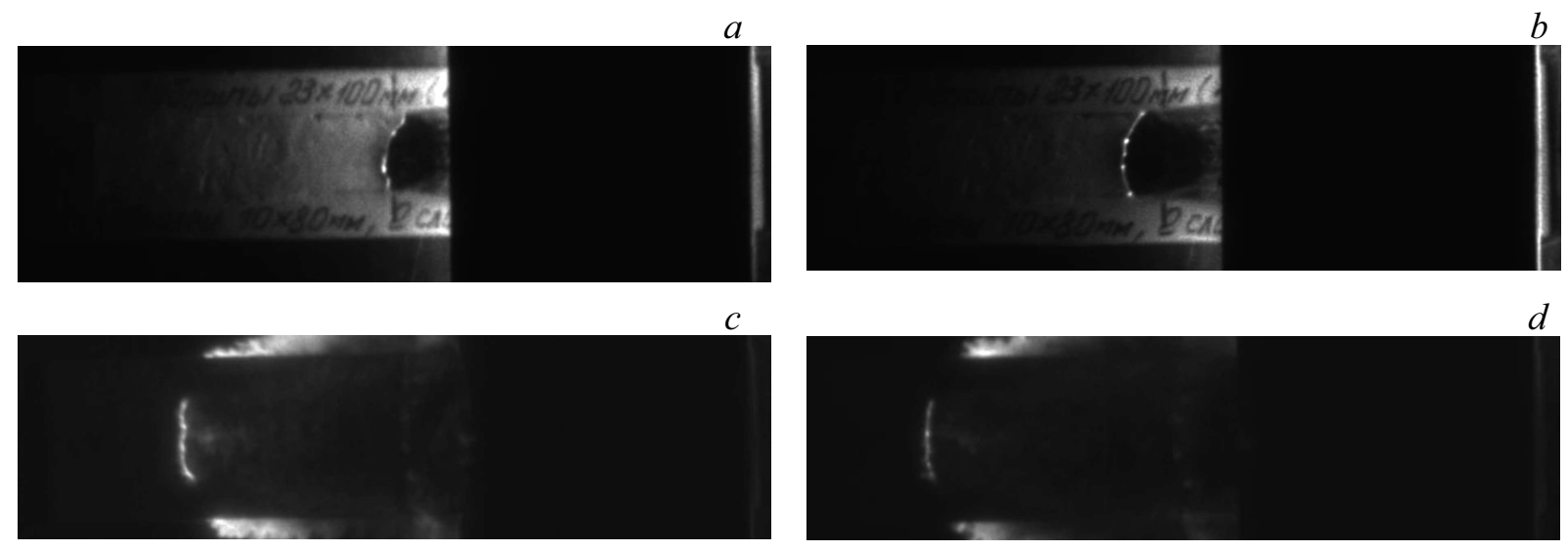

Рис. 2. Кадры регистрации детонации пленки состава ВС-2 камерой Наногейт 22/2 в опыте № $1 . a-10 \mu \mathrm{s}, b-11 \mu \mathrm{s}, c-17 \mu \mathrm{s}$, $d-18 \mu \mathrm{s}$.

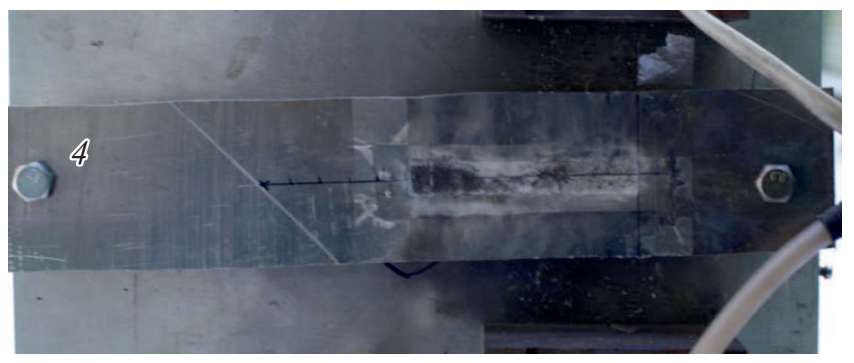

Рис. 3. Вид пластины-свидетеля после взрыва пленочного заряда № 4 состава ВС-2.

оптической камеры Наногейт 22/2 (Россия) и сигнал широкодиапазонного электронно-оптического фотометра ШЭОФ-ЗК (Россия) в момент воспламенения состава ВC-2. Блок согласования запускал цифровой осциллограф и камеру.

В опытах с зарядами № 1-4 было зарегистрировано время задержки инициирования меньше $3 \mu$ s и распространение детонационной волны в пленках состава ВС-2.
В качестве примера на рис. 2 представлены результаты регистрации детонации камерой Наногейт 22/2 в опыте № 1. Время отсчитывалось от момента подачи сигнала на запуск лампы-вспышки. Из рис. 2 видно, что детонационный фронт был искривлен и изменялся во времени.

Среднее экспериментальное значение скорости перемещения фронта детонационной волны в зарядах № 1-4 составило $\sim 4375$ и $\sim 4505 \mathrm{~m} / \mathrm{s}$ для пленок толщиной $\sim 0.55 \mathrm{~mm}$ (заряды № 1 и 2), а для пленок толщиной $\sim 0.82 \mathrm{~mm}$ (заряды № 3 и 4) скорость фронта $\sim 4221$ и $\sim 4281 \mathrm{~m} / \mathrm{s}$. На основании полученных результатов можно предположить, что на скорость детонации более тонких пленок (заряды № 1 и 2) оказывает дополнительное влияние скорость звука в подложке $(\sim 5000 \mathrm{~m} / \mathrm{s})$.

На заключительном этапе исследований была проведена оценка максимальной деформации пластинсвидетелей под действием нормальной ударной волны пленочных зарядов (рис. 3).

Было показано, что после испытаний в зарядах № 1 и 2 глубина отпечатка составила $2.4 \mathrm{~mm}$ для обоих зарядов, а в зарядах № 3 и 4 глубина отпечатка составила 5.3 и $6.8 \mathrm{~mm}$ соответственно, что доказывает необ- 
ходимость продолжения работ для выяснения причин различного бризантного действия образцов одинаковой толщины в приведенных экспериментах.

Таким образом, впервые показано, что свет лампы-вспышки инициирует в пленке пиротехнического состава ВС-2 детонацию, вызывающую деформацию алюминиевой пластины-свидетеля, величина которой напрямую зависит от толщины пленочного заряда состава BC-2.

\section{Финансирование работы}

Работа поддержана Российским фондом фундаментальных исследований (грант 17-03-00566).

\section{Конфликт интересов}

Авторы заявляют, что у них нет конфликта интересов.

\section{Список литературы}

[1] М.А. Илюшин, И.В. Целинский, Патент RU № 2225840 C2 (2004).

[2] S.R. Ahmad, M. Cartwright, Laser ignition of energetic materials (John Wiley \& Sons, Chichester, 2015).

[3] С.И. Герасимов, М.А. Илюшин, В.А.Кузьмин, Письма в ЖТФ, 41 (7), 66 (2015).

[4] М. Илюшин, И. Шугалей, А. Судариков, Высокоэнергетические металлокомплексы: синтез, свойства, применение (Lambert Academic Publishing, Saarbrucken, 2017).

[5] S.I. Gerasimov, M.A. Ilyushin, V.A. Kuz'min, I.V. Shugalei, Cent. Eur. J. Energ. Mater., 12 (4), 671 (2015).

[6] С.И. Герасимов, В.А. Кикеев, А.П. Фомкин, ЖТФ, 86 (11), 125 (2016).

[7] R. Matyáš, J. Pachman, Primary explosives (Springer, Heidelberg, 2013). https://doi.org/10.1007/978-8-642-28436-6 